\title{
Resonancia y movilidad del pensamiento
}

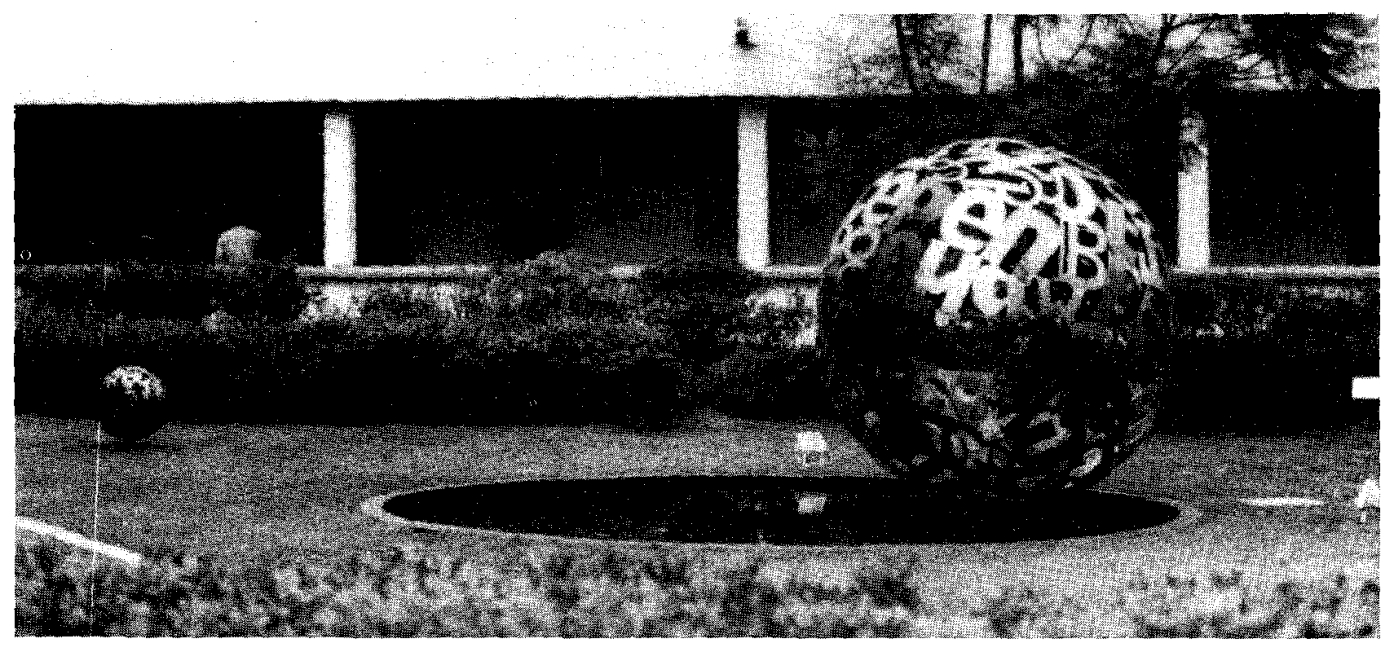

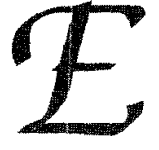

1 Centro de Enseñanza para Extranjeros tiene el placer de recibir a todos ustedes en este día tan especial para que sean testigos de la inauguración de la escultura conmemorativa de nuestro octogésimo aniversario, acto, que hoy como testigo de honor, preside el licenciado Enrique del Val, Secretario General de la UNAM.

El Comité Organizador de los Festejos convocó a un concurso al claustro de maestros escultores de la Escuela Nacional de Artes Plásticas, para presentar un proyecto escultórico de intervención de espacio en conmemoración de los primeros ochenta años de fundación del Centro de Enseñanza para Extranjeros, cuyas bases se publicaron en la Gaceta UNAM, el 28 de mayo del año 2001.

Como respuesta obtuvimos nueve proyectos, de los cuales el Honorable Jurado Calificador decidió otorgar a la maestra María Eugenia Gamiño Cruz el premio ganador como el mejor proyecto, por su moderno concepto de instalación.

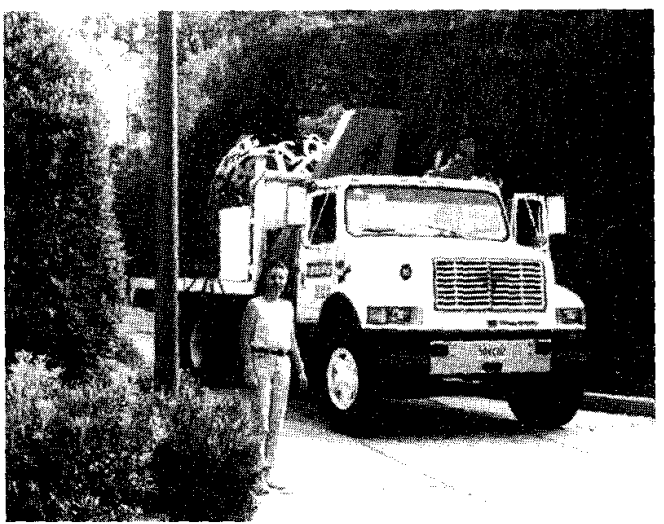

María Eugenia Gamiño durante el arribo de su conjunto escultórico al CEPE de Ciudad Universitaria

De esta manera, la maestra Gamiño trabajó con empeño su escultura que denominó Resonancia y movilidad del pensamiento. Como ustedes pueden apreciar, el proyecto comprende una construcción de metal sobre un espejo de agua. Consta de una esfera de dos metros de diámetro conformada por letras de aluminio, latón, cobre y acero, una esfera de 30 centíme- 


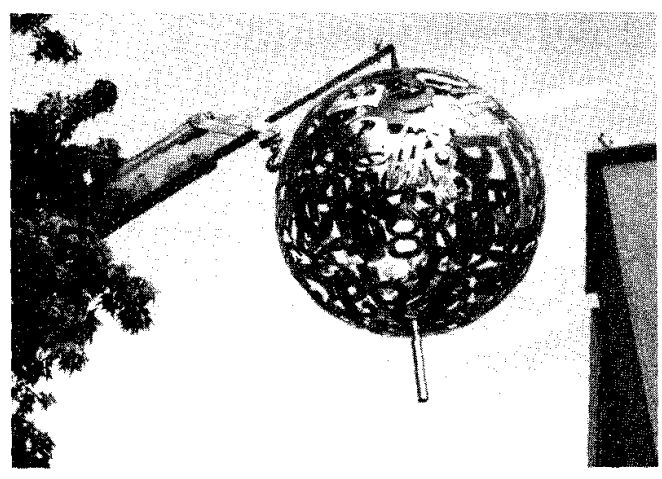

tros de diámetro y otra de 45 centímetros para que el espectador haga un recorrido visual $y$ unifique el espacio.

Resonancia y movilidad del pensamiento refleja, de una manera artística, la labor de nuestro Centro, las letras suspendidas en un espejo de agua proyectan la diversidad de lenguas de los alumnos del CEPE $y$, a la vez, la unidad que se logra con el aprendizaje del español en nuestras aulas. La esfera representa también un mundo que nos recuerda los distintos países de origen de nuestros alumnos, al igual que el

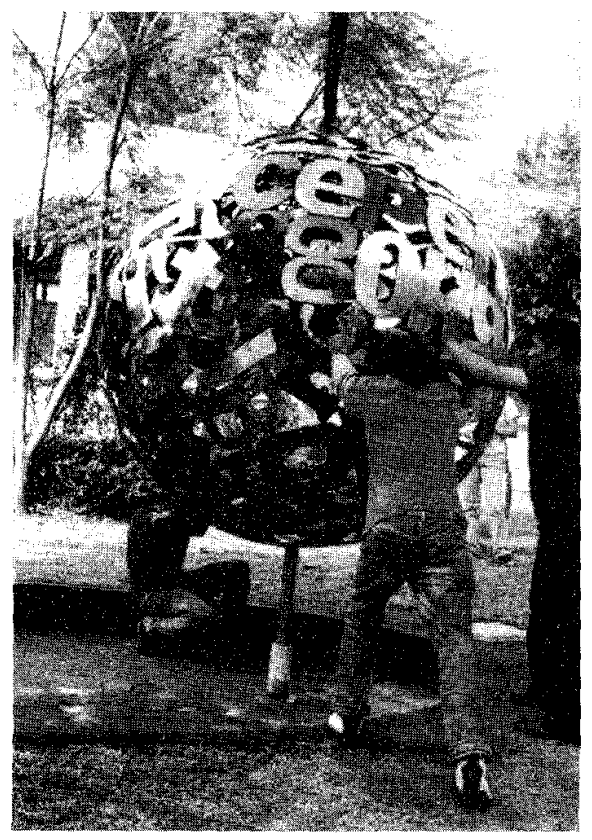

CEPE, durante estos ochenta años, ha logrado difundir la cultura mexicana a casi todos los rincones del planeta.

Es por ello que nos enorgullece inaugurar esta bella escultura como símbolo material, tangible y conmemorativo de nuestro Centro.

Quiero agradecer a la honorable Comisión de Adquisición y Mantenimiento del Patrimonio Artístico de la Universidad por el esfuerzo realizado durante la larga jornada en que se presentaron los diferentes trabajos, también a

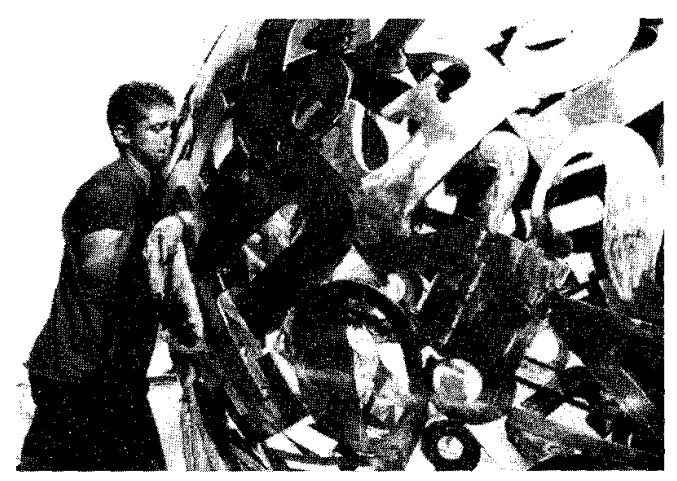

la Coordinación de Difusión Cultural por su invaluable apoyo; de manera muy especial, al maestro Eduardo A. Chávez Silva, Director de la Escuela Nacional de Artes Plásticas de la UNAM por su amplia orientación desde que este proyecto fue concebido como una idea hasta que cristalizó en la escultura que hoy se inaugura; al arquitecto Juan Felipe Leal Fernández, por sus valiosas reflexiones académicas y su gran apoyo en este proyecto; a la licenciada Dela Lagunes, por su guía a lo largo de todo el proceso del concurso, y en particular, a aquellas personas que en este hermoso proyecto tuvieron una participación directa en sus diferentes etapas: el licenciado César Benítez, la maestra Waltraut Rosas, Mayavel Saborío y la licenciada Silvia Fernández, la señora Rosa Lina Sánchez y la maestra Carmen Bermejo. 


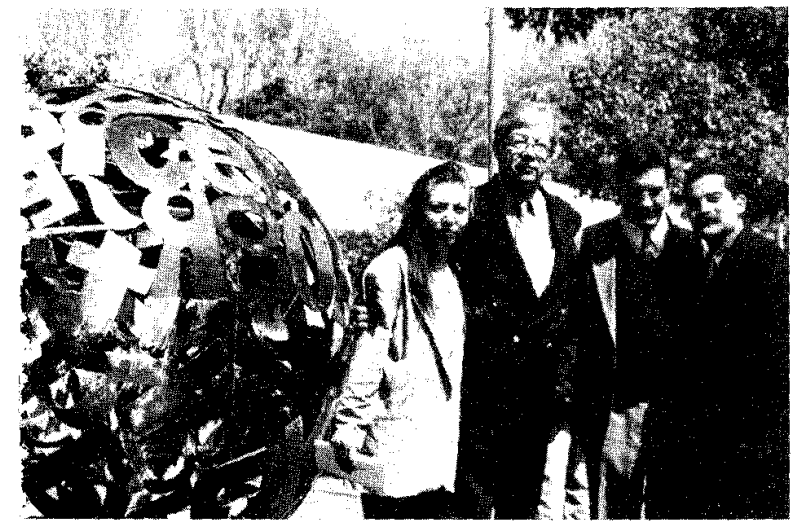

La escultora Gamiño flanqueada por el Mtro. Eduardo Chávez Silva y el Dr. Guillermo Pulido

Por supuesto, mi agradecimiento a todos los que diariamente contribuyen a que las labores académicas y administrativas en este Centro se realicen acorde a la misión que nos ha encomendado nuestra Universidad Nacional.

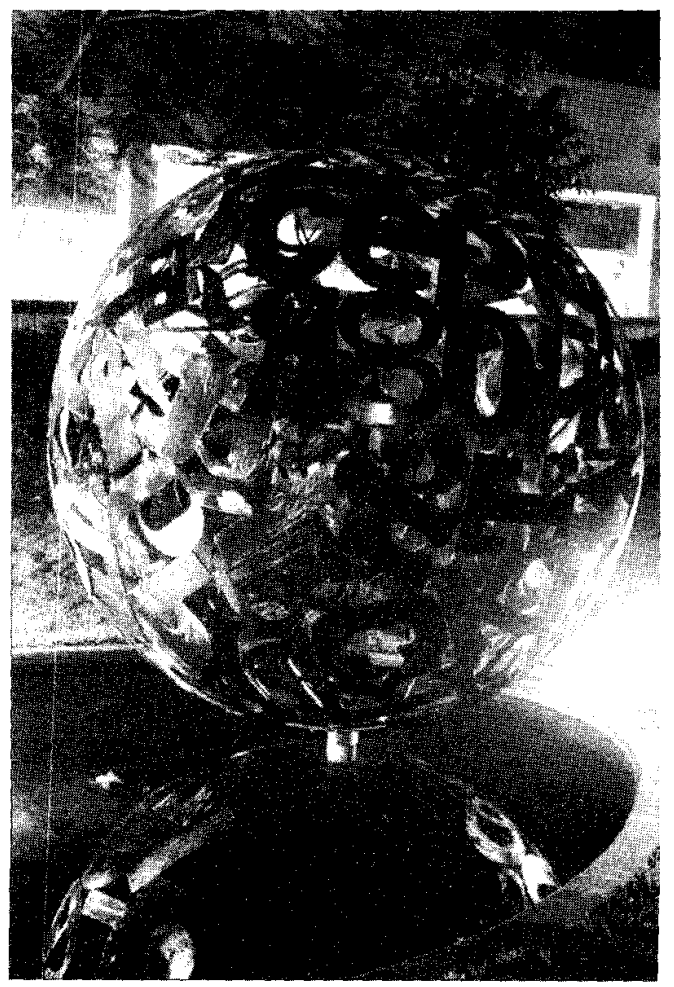

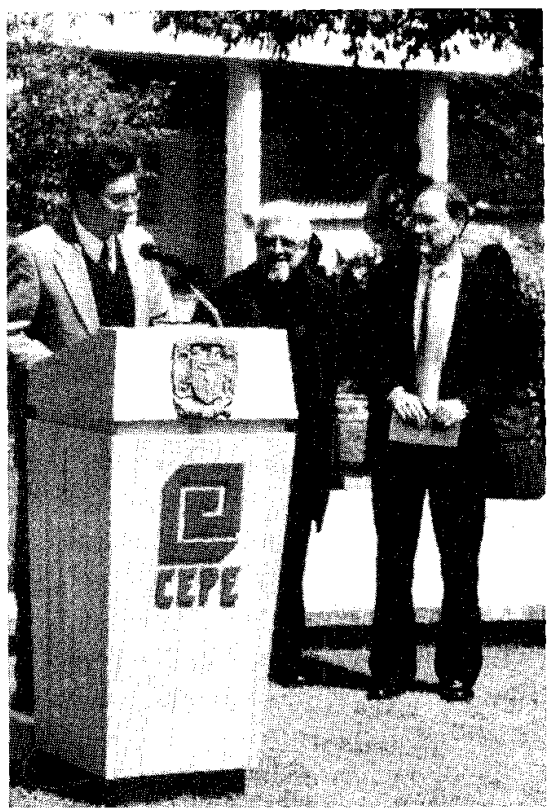

Dr: Guillermo Pulido, Mtro. Felipe Garrido y el Lic. Enrique del Val, Secretario General de la UNAM, quien apoyó las conmemoraciones del 80 aniversario del CEPE

Antes de ceder la palabra al distinguido catedrático universitario, escritor y amigo, Felipe Garrido, quiero expresar el agradecimiento de nuestra comunidad al licenciado Enrique del Val, por el apoyo otorgado por la Secretaría General, a su cargo, para la consecución de las metas que este Centro se ha propuesto en la administración del Dr. Juan Ramón de la Fuente, rector de nuestra Máxima Casa de Estudios

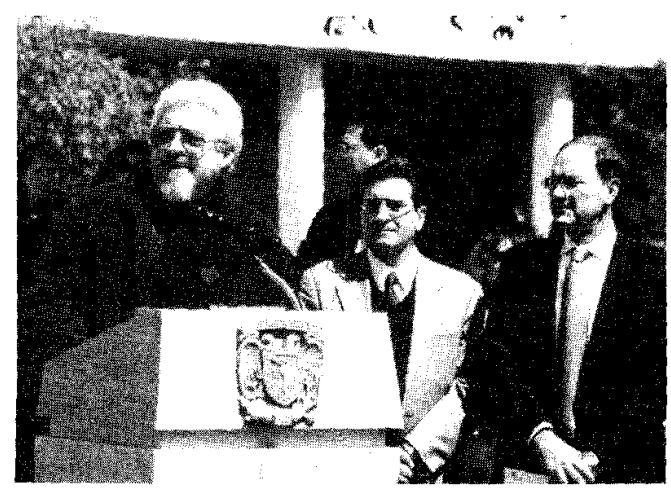

